\title{
UN DEBATE ALREDEDOR DE LAS FORTALEZAS Y LAS DEBILIDADES DE LAS ENCUESTAS ELECTORALES EN AMÉRICA LATINA
}

Manuel Mora y Araujo ${ }^{1}$, Eduardo Fidanza, Marta Lagos, Carlos Meléndez, Fabián Echegaray e Ignacio Zuasnabar

\section{Manuel Mora y Araujo}

Se me ha sugerido que, además de coordinar o moderar este panel, haga una pequeña introducción al tema que nos convoca: discutir sobre las fortalezas y las debilidades de las encuestas electorales. Las fortalezas son muy conocidas y me parece que no hace falta referirse a ellas. Los 80 años de vida de las encuestas -antes de los años treinta del siglo pasado no había encuestas- me parece que son testimonio de esta fortaleza. Las encuestas se inventaron en los años treinta; 30 años después eran todavía una curiosidad; 40 años después comenzaban a ser, en algunos lugares, una herramienta de relativa difusión y, muy recientemente, hará 20 o 30 años, pasaron a ocupar un rol protagónico en los procesos políticos en todas partes, incluyendo países como Cuba o la Unión Soviética. Esto habla de las fortalezas de esta herramienta, que pasó claramente a ocupar un lugar.

\footnotetext{
${ }^{1}$ En mayo de 2017, cuando este número de la RLOP ya estaba en prensa, falleció Manuel Mora y Araujo. Reconocido como uno de los padres fundadores de los estudios de opinión pública en la Argentina, Manolo como le deciamos todos, contribuyó decisivamente a la introducción en el país de muchos de los métodos de la ciencia social moderna y de las encuestas como herramienta para el conocimiento de la opinión pública. Manolo enseñó y formó investigadores en diversas instituciones: la Universidad de Buenos Aires, el IDES, la Fundación Bariloche, la Universidad Torcuato Di Tella - de la que fue Rector- la Universidad del CEMA. También participó y asesoró, siempre con empuje y ocupando diversas posiciones, en instituciones como Poder Ciudadano y Compromiso, asi como en emprendimientos intelectuales relacionados con los estudios científicos de la opinión pública. Su participación en la fundación y consolidación de WAPOR Latinoamérica fue decisiva. Manolo nos dejó un legado; el legado de un hombre brillante y, sobre todo, generoso.
} 
Un lugar que tiene que ver, básicamente, con 3 funciones: la primera es la de entender al mundo, convirtiéndose en una herramienta más a disposición de los analistas de los procesos históricos. La segunda función, que me parece que es fundamental, es la de servir a las estrategias políticas. Esta función de la encuesta es muy importante y vino asociada a cambios muy profundos en los procesos de organización política en el mundo. Yo no registro demasiadas debilidades, al menos por el momento, en relación a esta función, y desde hace 40 o 50 años se usan encuestas como respaldo para la toma de decisiones estratégicas de las campañas políticas.

La debilidad mayor de las encuestas va a estar asociada a su tercera función, que es el pronóstico electoral, esto es, anticiparse a lo que va a pasar. Esta es una función muy demandada en las sociedades; a la gente le interesa muchísimo la encuesta como ventana para mirar la realidad del mundo. El uso estratégico de las encuestas es algo medio misterioso, hay mucha mitología, pero la gente no tiene mucha información. En cambio esta función de pronóstico es muy demandada y, de hecho, a las encuestas se las está juzgando por su desempeño en esa función. Cuando en un país hay resultados electorales no previstos por las encuestas, las encuestas van al banquillo de los acusados. Esto está pasando cada vez más en todo el mundo. Entonces, me parece que este es el foco en el cual esta mesa debe concentrarse.

Yo quiero señalar dos cosas. La primera es que me parece que hay problemas técnicos que tienen mucho que ver con los cambios en la cultura en la que vivimos y que afectan la viabilidad para aplicar este método. Este es un tema muy obvio: hoy es más complicado que en el pasado obtener buenas muestras. Los métodos de recolección de datos se han diversificado, hay una mayor diversidad y todo eso produce mucha desviación estadística y muchos resultados no son consistentes. Esto confunde a la gente y repercute en la idea de que esta herramienta está, por así decirlo, en una situación de debilidad. 
También se podria hablar de la relación competitiva entre las encuestas como fuente de información y pronósticos y los medios de prensa. Pero ese es un aspecto secundario. El otro aspecto que quiero subrayar, además de estos aspectos técnicos, es que esta función de la encuesta como anticipo de lo que va a suceder -función que a la gente le divierte o le interesa mucho- está en tensión con la capacidad de la encuesta para servir a las estrategias electorales. El profesional que se maneja estratégicamente está buscando cambiar la realidad, está buscando que suceda algo que no sucedería si no se hace nada. Ese es el sentido de la intervención estratégica. La encuesta está pretendiendo saber qué va a pasar antes de que no pase nada. Esto es claramente algo que entra en contradicción con lo primero. Esta contradicción, creo yo, genera problemas serios para las encuestas: si la encuesta tiene éxito y pronostica qué va a pasar es porque algunas estrategias fracasaron claramente; y si las encuestas son exitosas, seguramente algunas fracasan porque no pasa lo que anticiparon que iba a suceder antes de que las estrategias tuvieran efecto.

Creo que alrededor de esto hay mucho para analizar, investigar y discutir y que este es un tema en el cual deberíamos enfocarnos.

\section{Eduardo Fidanza²}

Como forma de aportar al debate, voy a plantear 7 u 8 puntos más o menos rápidamente. Parto del mismo lugar que Manuel: no es necesario demostrar las fortalezas de las encuestas; estoy aquí con un conjunto de colegas que desde hace años trabajan con encuestas de opinión pública, que han construido bases de datos, han hecho seguimientos de los estados de la opinión pública a lo largo de los años. Esto hace de las encuestas de opinión pública una herramienta formidable. Creo que, complementando las encuestas con estudios cualitativos, tenemos un panorama de lo que una sociedad es.

\footnotetext{
${ }^{2}$ Director de Poliarquia, Argentina; columnista del diario La Nación.
} 
El punto, como se decía recién, es la encuesta política en función de un pronóstico; es por eso que seremos juzgados, absueltos o condenados. Y los medios de comunicación están siendo muy severos con las encuestas. Porque las encuestas de opinión pública creo que terminaron formando parte de la sociedad del entretenimiento. Es divertido saber si las encuestas acertaron, si se equivocaron, por cuánto se equivocaron, etc. Estamos sometidos a esta cuestión.

Mi primer punto es un punto obvio. Recién Manuel mencionaba el origen de las encuestas de opinión pública, básicamente en Estados Unidos. Yo agregaría que en aquella época la encuesta suponía como encuestado a un ciudadano relativamente interesado en la política, capaz de tomar una decisión autónoma y relativamente informado, dentro de un sistema de partidos estable y con un claro bipartidismo. Es en este contexto que empezaron las encuestas. Pero estamos al cabo de un largo proceso por el cual ese votante con esas características hoy se transformó en el votante posmoderno, volátil, desinteresado, cambiante, desconfiado y transgresor. Entonces, creo que pronosticar la conducta de este encuestado del siglo XXI es más complejo que pronosticar la conducta de aquel. Claro que esto es relativo, ya que las encuestas de aquellas épocas, más allá de sus grandes aciertos, cometieron serios errores. Pero a mí me interesa el trasfondo sociocultural de esta cuestión.

Un segundo punto correlacionado con esto es que las identidades partidarias y políticas están licuadas. Yo recuerdo cuando nosotros empezamos a trabajar con las encuestas, en 1984 o 1985, existía el peronista, existía el radical y existía la identidad. Bien: esas entidades están licuadas. Están licuadas no solamente desde la demanda o desde el encuestado, están licuadas también desde la oferta, están licuadas en la medida en que los partidos hacen coaliciones y que esas coaliciones muchas veces son contingentes o inestables. Por otro lado, influye el sistema con que se vota, porque no todas las elecciones tienen 
las mismas características, porque no es lo mismo cuando hay muchos candidatos que cuando hay pocos, porque hay además candidatos que vienen de un mundo que no es el de la política. Esto, que llamo licuación de identidades, es entonces el segundo punto que quería señalar.

Mi tercer punto, que Manuel tocó, es el cambio en el uso de las encuestas. Coincido en que la encuesta es una herramienta de diagnóstico que se usa en las campañas electorales para tomar decisiones pero también es una herramienta del marketing. Todos los que trabajamos en esto sabemos que, en muchos casos, los clientes políticos vienen a contratarnos para tener encuestas que muestren los resultados que ellos quieren ver, y quieren que estos resultados se publiquen en los medios para ayudarlos a ganar la elección. Algunos colegas han aceptado esto, con lo cual terminaron teniendo amos en lugar de clientes. Voy a decir algo que ustedes saben: en esta última década el kirchnerismo ha sido bastante complicado en relación a este tema, ejerciendo presión sobre los encuestadores, amenazando al profesional con suspender contratos si no modificaba los datos. Estas cosas también han sucedido o le suceden a nuestra profesión. Actualmente estamos viviendo una etapa de reconstrucción de las estadísticas públicas y de sinceramiento, ${ }^{3}$ un nuevo pluralismo político que espero no sea una primavera. Yo creo que muchos de nosotros sentimos que nos sacan la mano del cuello y que vamos a poder de alguna manera ejercer nuestra profesión mejor. Pero, atención, este detalle de que la encuesta se convierta en un medio de publicidad política es, a mi modo de ver, nefasto para las encuestas.

\footnotetext{
${ }^{3}$ En enero de 2007, en un contexto inflacionario innegable, el gobierno intervino el Instituto Nacional de Estadísticas y Censos (Indec), consumando arbitrariamente un cambio en la metodología de medición de los precios. A partir de ese momento, se observaron grandes discrepancias entre las estadísticas oficiales y las privadas, tanto en relación a la tasa de inflación como a la tasa de crecimiento o el nivel de empleo. Con el cambio de gobierno a fines de 2015, el Indec ha sido "refundado", dejando atrás un período de alteración de las estadísticas púbicas y recuperando el compromiso de transparencia en relación a los datos oficiales.
} 
Un cuarto punto es que nuestros encuestados han perdido la inocencia. En un contexto en el que la encuesta se desacreditó, en el que la gente sabe que es algo falible, algo que forma parte de un pronóstico deportivo, yo creo que nuestros encuestados están preparados o dispuestos a mentirnos más que en otras épocas. Además, están atosigados de llamadas telefónicas, de consultas, de estímulos. Sería bueno contar con un estudio que mostrara qué lugar ocupan nuestras encuestas en esa serie de estimulación permanente. Hasta hace algunos años, uno tocaba el timbre en la casa y era una especie de novedad: ivino el encuestador! Ahora, en esta serie interminable de estímulos, no sabemos dónde estamos ubicados. Eso pone a nuestro objeto de investigación en una situación, digamos, de pérdida de inocencia; el encuestado ya no es más un inocente dispuesto a que lo investiguemos; es un calculador que, si nos puede tender una trampa, nos la va a tender.

Mi quinto punto son las barreras y los limites para llegar a los encuestados. Este punto está vinculado con mi sexto tema, que yo llamo el crepúsculo de la encuesta domiciliaria como encuesta normativa. Hasta hace unos años, cuando uno tenía dudas, hacía una encuesta domiciliaria. Y esa encuesta domiciliaria de alguna manera se transformaba en el pronóstico en el que uno tenía más convicción, porque, metodológicamente, era la encuesta más legítima, la más compleja, la que cumplía los pasos que se supone que el método tiene que cumplir. Recuerdo que, cuando yo empecé, hace ya varios años, hablaba con señoras mayores que hacian el trabajo de campo y que, cuando se empezó a trabajar con cuotas de sexo y edad, estas mujeres estaban horrorizadas, como si eso fuera un sacrilegio. Las cuotas son el fin de las encuestas, me decía una de ellas. Bueno, ya pasamos las cuotas y si estas señoras supieran que usamos el IVR también, para orientarnos, dirían que eso es la estafa total. Lo que quiero señalar es que tenemos barreras para llegar con la encuesta domiciliaria; sabemos que no se pueden hacer en las grandes ciudades, donde la gente vive detrás de sus miedos y de sus rejas. 
Hoy las encuestas domiciliarias subrepresentan a los sectores altos en tanto la encuesta telefónica subrepresenta a la gente que no tiene teléfono. El IVR lo usamos pero en vista de sus problemas metodológicos tampoco podemos confiar demasiado. Entonces, hay un problema con las técnicas de recolección de datos. Es verdad que hay nuevos métodos que en algunas zonas tienen éxito, por ejemplo, las encuestas en línea en la ciudad de Buenos Aires permiten pronósticos electorales relativamente confiables. Pero, en sintesis, hay que ver qué destino van a tener todas estas nuevas metodologías y cómo van a evolucionar.

Hay un último punto que también es interesante: la transformación del rol profesional y del modo de producción de la encuesta. ¿Cómo eran las encuestas que se hacían hace 30 años, las que hacían Manuel Mora y Araujo o Edgardo Catterberg, los padres fundadores de los estudios de opinión pública en la Argentina? Eran una obra de arte, firmada por una persona con antecedentes, formación académica y experiencia profesional. Bueno, esto cambió. Las computadoras pasaron a ser de escritorio y vinieron los programas que todos podemos manejar; hoy alguien con una experiencia minima de trabajo termina siendo titular de una consultora. Eso es sin duda un cambio en relación a cómo se hacían las encuestas y creo que esa transformación del modo de producción de las encuestas, esos cambios en la organización de las empresas encuestadoras, son también un dato a analizar.

Termino con lo siguiente: tenemos desafíos por delante, desafíos que esta profesión debe tratar de resolver. Cuanta más democracia haya, cuanto más prestigio tenga la política, mayor prestigio tendrán las encuestas; en la medida en que se desprestigia la política este instrumento, que trabaja en los engranajes de la política, no puede prestigiarse. De modo que hago votos para que en la Argentina, a partir del cambio político que ha habido, con un clima de mayor sinceridad y transparencia y con la reconstrucción de las estadísticas públicas, las encuestas de opinión también puedan empezar a levantar vuelo. 


\section{Marta Lagos ${ }^{4}$}

Voy a retroceder un poco para poder responder a la pregunta.

Las encuestas pueden medir 5 cosas, una de las cuales es el comportamiento. En general, las encuestas no miden comportamiento sino más bien opiniones, actitudes, valores, conocimientos, información. El comportamiento, sin embargo, es lo que les dio, en sus orígenes, legitimidad a las encuestas. Nacieron como válidas precisamente porque fueron capaces de medir el comportamiento de los votantes en las elecciones. Todo lo que sucede con las encuestas a partir del momento en el que se anticipa el resultado de una elección tiene que ver con su capacidad para reflejar una realidad determinada en un momento determinado. Es una realidad verdadera que son capaces de reflejar: ese es el capital de la encuesta.

El reclamo del público, de los usuarios de encuestas, es que "deben" ser capaces de cumplir esa promesa. Lo que está puesto hoy en cuestión no es ese capital, sino la metodología que se usa para cumplir esa demanda. El reclamo es la confirmación de su capital.

Gallup diseñó esta metodología que, como dice Eduardo, es una obra de arte y lo sigue siendo. La encuesta electoral es un arte, más allá de la metodología. Nuestra generación de encuestadores no hemos desarrollado una alternativa que incorpore las complejidades del presente a esa metodología.

Hemos introducido la cuota, por ejemplo, pero, cuando hablamos de cuotas, es importante tener en cuenta que cuando la estadística es buena, cuando el censo es bueno, cuando la muestra está bien sorteada, la cuota funciona. Los matemáticos no pueden explicar por qué funciona la cuota, pero funciona. No obstante, tenemos una falla, porque la matemática desde hace mucho tiempo podria haber construido el margen de error para una encuesta con cuo-

${ }^{4}$ Directora fundadora de la Corporación Latinobarómetro, coordinadora de GBS Globalbarometers. 
tas, que no tiene margen de error más que hasta el segundo nivel. No hemos desarrollado la teoría necesaria para explicar lo que hacemos en la realidad y por qué funciona. Según la teoría matemática, la cuota no debería funcionar. De la misma manera (ver https://yougov.co.uk) se inventaron las encuestas por correo electrónico, que tampoco deberían funcionar si se hacen sobre la base de un universo parcial (no todos tienen correo electrónico). Pero funcionan.

Cuando aparecieron las encuestas de YouGov en el año 2000 en Inglaterra, toda la industria decía que eso era una barbaridad, pero fue la que más cerca acertó las primeras elecciones que midió. Entonces, aquí también hay un método de acercarse a esa realidad que ningún matemático puede explicar. La práctica se comió a la teoría. Nuestros antecesores, Lazarsfeld, Gallup y compañia, tenían una teoria que transformaron en un método; nosotros inventamos una práctica que funciona, sin teoría. Claramente, ahí está el problema. La modificación del método original sobre la base de la práctica. Unas que funcionan; otras que no.

La industria se ha desarrollado con mucha velocidad; se introdujo mucha tecnología y no fue acompañada por las universidades, que se quedaron atrás. De hecho, la mayor parte del desarrollo de las encuestas en América Latina sucedió fuera de las universidades, por eso es que hay que aplaudir esta iniciativa, este encuentro. Hay muy pocas iniciativas dentro de las universidades; generalmente son los encuestadores los que van a las universidades a explicar cómo hacen lo que hacen. Y la verdad es que, para no dar el secreto, explican la mitad. Entonces, yo pregunto: ¿por qué nos equivocamos? Nos equivocamos en primer lugar porque no compartimos nunca nuestro secreto. El que tiene un algoritmo para predecir las elecciones en su país no se lo cuenta ni a la almohada; tampoco lo documenta. Esa es la parte del arte que mencionaba Gallup. No hemos intercambiado, no hemos compartido, no hemos documentado, no hemos desarrollado la matemática para ex- 
plicar los márgenes de error; y ahora resulta que la cosa no está funcionando. No tenemos respaldo al cual retroceder, si no es a los fundadores. Nos quedamos con Lazarsfeld y con Gallup y con esta ortodoxia de que, si no la aplicamos, no resulta; pero, si la aplicamos, ocurre que no resulta porque ahora todo es volátil y si uno no hace la encuesta tres días antes de la elección se equivoca. Estamos atrapados entre el tiempo y la metodología. Tenemos que hacer que ambos sean compatibles.

La volatilidad del voto, del mundo moderno, la globalización, ¿no permiten anticipar? Efectivamente, el instrumento de la encuesta mide lo que sucede en el minuto en el que se levanta. No ve el futuro. Lo que sucede es que el votante antiguamente sabía con anticipación lo que iba a hacer, había lealtad de partido, pertenencia a movimientos, liderazgos fuertes, que producian esa anticipación. Una gran cantidad de votantes, desde la Segunda Guerra Mundial, supieron cual sería su voto en sistemas políticos estables, con políticos de gran liderazgo. Las encuestas podían medir ese comportamiento. La encuesta no anticipa; se supone que el estudio lo que hace es medir el comportamiento estable en una sociedad no volátil, no cambiante. En los años cincuenta, después de la guerra, las sociedades europeas eran una taza de leche, los habían matado a todos, no costaba mucho anticipar porque no había cambio en el comportamiento; de hecho, uno podía hacer una encuesta una semana antes y sucedía exactamente, con 0,1\% de diferencia, lo que el entrevistado había dicho. No es un problema de mentira, es un problema de que la gente hoy en día es volátil. Hoy los partidos han perdido adherentes, lealtad; hoy los líderes siguen las encuestas en vez de conducir; hoy los candidatos son muchos; hoy no hay certezas sino incertidumbres. Los votantes tienen incertidumbres brutales, no saben qué van a hacer al día siguiente y, por lo tanto, tampoco saben cómo van a votar. La política se volvió volátil y no tenemos una teoría sobre eso, entre otras cosas porque las ciencias sociales, las ciencias políticas, la sociología no nos han acompa- 
ñado, han dejado esta área gris, no han incorporado estos temas. Medir una o dos semanas antes de la elección es hoy día un alto riesgo, porque la gente toma la decisión días y horas antes. Entonces, hay que medir lo más cercano posible al día de la elección. El mundo instantáneo.

Para volver a la sana doctrina tenemos que crear la teoría, cerrar las brechas matemáticas, hacer todas estas cosas que se han perdido en la vorágine de hacer las cosas sin documentarlas. Si uno les pregunta a los encuestadores que han acertado en Europa en los últimos 30 años ninguno está dispuesto a publicar cómo acertó. Nadie va a publicar su secreto; puedes hacer una charla académica pero nunca vas a describir el proceso numérico. Estamos, entonces, en una trampa que hemos creado nosotros mismos. Porque hoy en día los métodos conocidos, los procedimientos que tenemos no son suficientes para controlar la volatilidad del mundo que nos rodea. Creo que nos hemos creado esta trampa y tenemos que empezar a retroceder para ir llenando los vacios.

El tema de las cuotas no es menor; no ha habido desarrollos en ese campo. Y lo mismo ocurre con, por ejemplo, el tema de las muestras de teléfonos celulares: ¿qué pasa cuando una persona tiene dos números? ¿cómo se sortea adecuadamente? ¿cómo se hace un algoritmo para calcular la cantidad y el tipo de gente que, teniendo dos números de teléfono, debe ser sorteada como si tuviera uno? Esos métodos no existen; uno inventa sustitutos de métodos para tratar de seguir la regla más ortodoxa, pero esa regla no existe.

A esto se agregan otras cuestiones, como que la variedad de innovaciones que se agregan permite no distinguir entre lo auténtico y lo falso. A Stiglitz le dieron el premio Nobel porque dijo que cuando la gente no distinguía los neumáticos viejos de los nuevos, compraba neumáticos viejos. Lo que pasa con las encuestas es eso. Hay seudoencuestas: se arman consultoras con un señor que contrata 5 estudiantes y va por la calle haciendo entrevistas y dice: la encuesta de la empresa $\mathrm{X}$ dice que fulano gana. Los diarios publican todo, porque los medios de comunicación son 
muy perversos, no distinguen el neumático viejo del neumático nuevo, y la gente compra los viejos. Entonces, las consultoras que hacen el estudio caro, ese del arte como lo llama Eduardo Fidanza, no tienen ninguna posibilidad de imponerse con un producto de calidad. Hoy día, además, se equivocan, ayudando a los medios a no distinguir entre las que tienen un método y las que no usan método.

Para terminar: creo que hay un tema profundo que tiene sus vacíos y que nosotros, los encuestadores, tenemos que empezar a abordarlo mancomunada y colectivamente para ir solucionando uno a uno estos problemas. El más complejo, creo yo, es el tema de la volatilidad. Después del fracaso en las elecciones de 1992 los ingleses publicaron un informe muy interesante. Ahora, después del brexit, hicieron otro, en el que muestran que las encuestas se equivocaron porque fueron hechas bastante antes de las elecciones y la gente tomó la decisión muy cerca de ellas: http:// ukpollingreport.co.uk/blog/archives/category/what-wentwrong. Hay una gran volatilidad del voto. ¿Cómo hacer una encuesta tres dias antes de las elecciones y alcanzar a publicarla? Porque si no se va a lograr publicarla entonces no se hace la encuesta.

Estas son algunas de las cosas que tenemos que abordar para ir avanzando en esto que es un campo minado.

\section{Carlos Meléndez 5}

Coincido mucho con quienes me antecedieron; de hecho, tenemos varios puntos en común. Voy a hablar de los obstáculos que enfrentan las encuestas en general, centrando mis reflexiones en el caso peruano.

El primero tiene que ver efectivamente con la volatilidad, con hacer encuestas cuando no hay partidos. En casos extremos de crisis de representación política, como el caso peruano, los partidos políticos no existen. El APRA ha en-

${ }^{5}$ Investigador y docente de la Universidad Diego Portales, Chile. Columnista del diario El Comercio (Perú). 
trado en una severa crisis, el fujimorismo ha constituido un nuevo partido, pero, más allá de ellos, no existen partidos políticos sólidos. Si la identidad partidaria es el principal predictor del voto, nos hemos quedado sin el principal predictor político.

\section{Gráfico 1 \\ Intención de voto (2015-2016)}
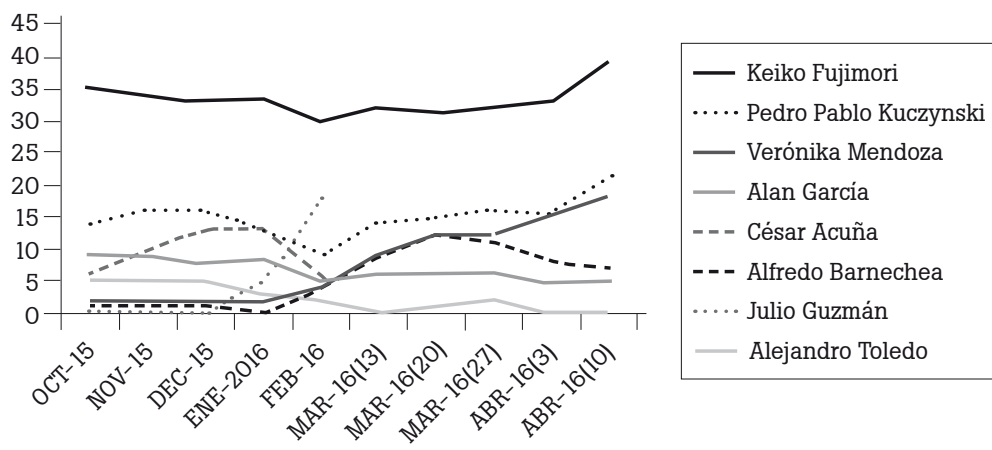

El gráfico arriba muestra la volatilidad de las preferencias electorales durante los tres últimos meses de la campaña. La línea de arriba, la negra continua, es la única línea más o menos estable; es la línea del fujimorismo. El fujimorismo ha generado una cierta identidad partidaria a su alrededor y es lo único más o menos estable. Todo lo demás son idas y vueltas. La línea negra discontinua es la de Pedro Pablo Kuczynski, que termina segundo y pasa a la segunda vuelta. Las otras líneas en tonos de grises son Alan García, Alfredo Barnechea, Verónika Mendoza. Entonces, evidentemente, poder predecir resultados electorales, con escenarios que van cambiando semana por semana, día a día, es muy difícil.

Se ven en el gráfico dos líneas (discontinuas) truncas. Estas refieren a otro de los obstáculos que debió enfrentar esta campaña. La campaña electoral peruana fue, en efecto, una campaña accidentada: comenzaron 19 candidatos y 
terminaron 10. Decían en Perú que eso parecía los Juegos del Hambre, porque cada semana se iba retirando alguno o se le quitaba la inscripción a algún partido. Las autoridades electorales, por ejemplo, terminaron suspendiendo a dos candidatos por infracciones administrativas; dos candidatos que tenían el $10 \%$ de intención de voto, lo cual en Perú ya es bastante, fueron suspendidos y se cancelaron sus candidaturas. Así, la campaña electoral, que comenzó el 15 de diciembre con 19 candidatos, terminó con 10 .

Esos fueron dos de los principales problemas que enfrentaron las encuestadoras. El tercero tiene que ver con un territorio bastante complicado; esto pasa en muchos países, pero hacer unas encuestas en Los Andes y en la Amazonia es mucho más complicado aún. En Perú se siguen haciendo las encuestas cara a cara; se hacen encuestas por teléfono, por Internet, pero las encuestadoras prefieren todavía el método convencional, que enfrenta la dificultad de la geografía para desplazar a los encuestadores respetando la aleatoriedad de la muestra.

Un cuarto obstáculo es la desconfianza que tiene la gente hacia las encuestadoras, entre otras cosas, alentada por los propios políticos. Por ejemplo, durante la campaña el mismo Alan García -cuando las encuestas no le favorecían- dijo que el dueño de una encuestadora le había ofrecido dinero para ponerlo "arriba en unas encuestas". Hubo incluso un juicio de por medio. 0 sea, algunas de las encuestadoras -las menos serias, obviamente- se han convertido en parte de la farándula de la política, del show business de la política y los políticos no tienen ningún reparo en estigmatizarlas, en acusarlas, en echarles barro. Algunas encuestadoras son serias, otras no; pero el problema es que todas terminan perjudicándose por esto.

Finalmente, un quinto reto es un reto metodológico general, que escapa al ámbito peruano: yo sí creo que la gente miente. Trabajo con encuestas desde la academia y creo que hay que cuestionar la premisa con la que uno estudia la opinión pública. ¿Por qué la gente le va a abrir la puer- 
ta a alguien que no conoce y le va a decir algo tan íntimo como a quién va a votar? Quizás fue así en algún momento; hace décadas uno podía generar cierta confianza, pero ahora es muy difícil que la gente sea totalmente sincera. Más bien hay que pensar técnicas o métodos para detectar la veracidad en las respuestas; ver qué porcentaje de sinceridad podemos aprehender en este ejercicio de las encuestas. En Perú hay antecedentes de grandes números mintiendo en encuestas decisivas. En el año 2000, cuando se daba a Alberto Fujimori como perdedor en estas elecciones y se anunciaba que Alejandro Toledo había ganado la elección, se detectó que el $10 \%$ al $12 \%$ de encuestados había mentido al responder su preferencia electoral. Este es el fenómeno del voto vergonzante, del voto oculto que hay por detrás de algunas candidaturas.

¿Qué hicieron entonces las encuestadoras peruanas frente a este escenario y a todos estos antecedentes? Planificaron dos tipos de instrumentos de recolección de información para el día de las elecciones: la boca de urna y el conteo rápido. Como ustedes saben, la boca de urna es una encuesta rápida que se realiza al momento de salir los votantes de los puestos de votación. Ipsos y GFK, que son dos de las principales encuestadoras del Perú, recolectaron 30.000 y 40.000 encuestas el día de la elección e hicieron, además, un conteo rápido del voto. El conteo rápido se hace a partir de una muestra de las mesas de votación; en el caso de Ipsos se tomaron 1.620 mesas de votación y en el caso de GFK, 2.400. Para dar una idea: se consideraron entre 600.000 y 700.000 electores de una población de 13.000.000 de electores, esto es, una muestra sorprendentemente grande. Y, efectivamente, los resultados fueron bastante alentadores. De hecho, el caso peruano fue una excepción si vemos el panorama global, ya que a las encuestadoras les fue muy bien. Y les fue bien en un escenario bastante volátil y complicado.

Lo que tenemos en el Gráfico 2 son los resultados, para la primera vuelta, de la boca de urna de Ipsos -línea de arri- 
ba-; en el segundo lugar, los del conteo rápido de Ipsos y, en el tercero, los datos oficiales. Si miramos las barras más oscuras que representan el apoyo a Keiko Fujimori, según el boca de urna fue 37,8 \%; según el conteo rápido, 39,6 \%. El conteo rápido efectivamente se acercó mucho al conteo oficial de la ONPE, que fue el 39,8 \%. Como ustedes pueden ver las diferencias en la primera vuelta fueron de décimas.

\section{Gráfico 2}

Resultados de Elecciones Presidenciales Primera Vuelta y Proyecciones de Ipsos (\%)

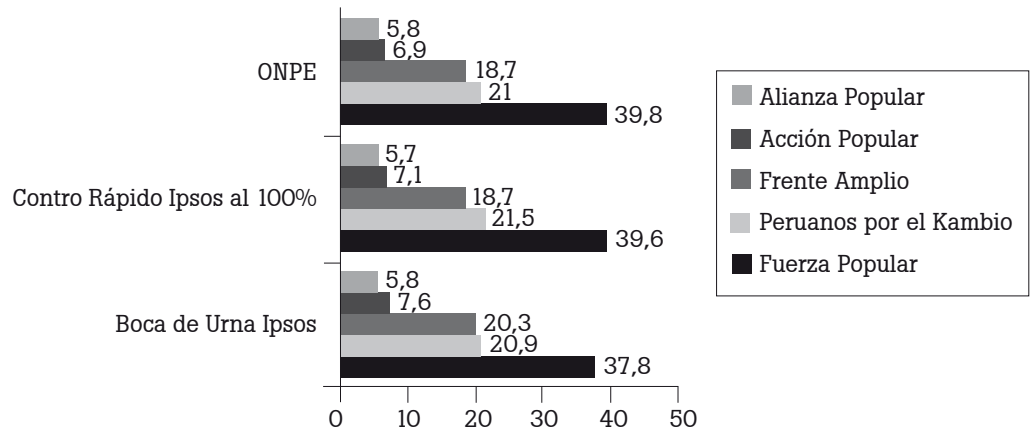

Gráfico 3

PPK: Resultados de Elecciones Presidenciales Segunda Vuelta y Proyecciones Encuestadoras

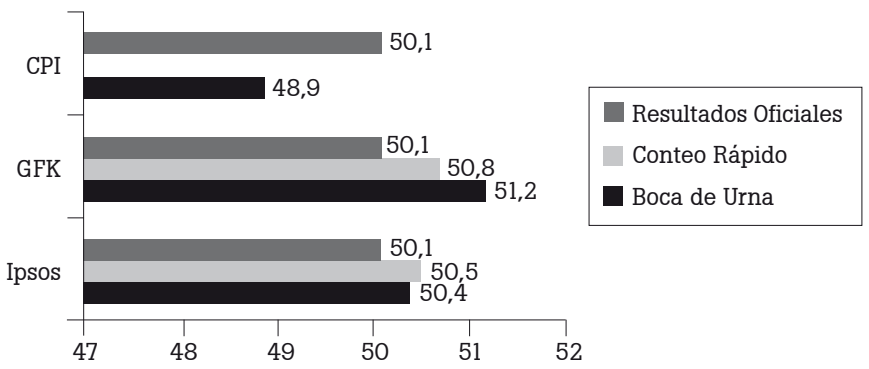


En el Gráfico 3, con los datos de la segunda vuelta, la precisión fue aún mayor. En esta segunda vuelta corrían dos candidaturas, la de Keiko Fujimori y la de Pedro Pablo Kuczynski, y la diferencia final entre ambas fue de solo 39.000 votos. En este caso, los resultados de las dos principales encuestadoras -Ipsos y GFK- fueron muy parecidos. En el boca de urna Ipsos, PPK obtuvo 50,4 \%; en el conteo rápido, 50,5\% y el dato oficial fue 50,1 \%. En GFK las distancias fueron similares.

Como ustedes pueden ver los resultados fueron bastante alentadores para estas empresas y les dieron bastante confianza a las personas que trabajan con encuestas en el Perú. Entonces, aquí viene la pregunta: ¿cómo hicieron para que les fuera tan bien? Yo trabajo con las encuestas desde la academia y conozco a quienes dirigen y trabajan en Ipsos y en GFK. Obviamente, no van a contar su secreto, no van a mostrar su algoritmo. Pero sí me confiaron algunas pistas que muestran por dónde pueden ir ciertas virtudes. En lo que todos coinciden es en el diseño muestral y en el trabajo de campo. Empezando con el diseño muestral, tiene que ser representativo. En el Perú hay una preocupación enfática por llegar al voto rural, porque es ahí donde mayores distorsiones se han generado en el pasado -en Colombia, por ejemplo, las encuestas erraron mucho porque no tienen una buena muestra en el campo- y dedican muchos recursos para hacer un trabajo específico en el campo, porque implica mucho más costos, mucha más logística para poder llegar a las zonas sorteadas y evitar reemplazos en las muestras.

Luego, hay un trabajo muy cuidadoso en asegurar que los entrevistadores no falseen información. La ventaja de Ipsos y de GFK es que hacen encuestas mensuales, inclusive en épocas no electorales. Entonces, pueden contratar y mantener equipos permanentes que se dedican solamente a hacer sus propias encuestas; eso les asegura cierta lealtad y mayores niveles de profesionalismo.

Por otro lado, se practican ponderaciones para ajustar posibles desviaciones, sobre todo entre los electores de la 
población que no tiene empleo, segmento que es, según ambas encuestadoras, el principal tergiversador de las predicciones. Otra recomendación es hacer el trabajo de campo lo más cerca posible al día de las elecciones, incluso dos días antes de la elección, si es posible. Finalmente, otra forma de generar confianza en las encuestadoras en Perú es que, a pesar de ser encuestadoras privadas, pusieron las bases de datos de las encuestas que realizan mensualmente a disposición en sus páginas web para evitar suspicacias. Eso aumentó la confianza y atenuó las críticas que se les hacían.

Para finalizar, quiero hablar de cuáles son, a mi entender, los desafíos que enfrentan las encuestas. Un primer elemento a tomar en cuenta es que debemos aprender a mejorar las preguntas que hacemos. Porque la política se ha vuelto una mala palabra, hay mucha carga de estigmatización social sobre muchos fenómenos de la política -esto tiene que ver con el clientelismo, con la coerción política que se practica en muchos países, etc.-, entonces, hay que ver cómo mejoramos las preguntas que hacemos. Una forma quizás de dar un paso adelante es ir hacia los diseños experimentales. Ya sé que en algunos países -sobre todo desde la academia- se practican experimentos de lista y metodologías por el estilo, que de algún modo contribuyen a atenuar la estigmatización social que existe en relación a algunos temas particularmente polémicos. Quizás esa puede ser una vía hacia dónde ir.

Otro desafío tiene que ver con la supervisión y la verificación del trabajo de campo. Los encuestadores para Lapop, por ejemplo, aplican los cuestionarios desde celulares o tabletas. Esto permite una verificación en línea, casi en vivo, del trabajo que está haciendo el encuestador. Y ayuda a tener no solo un mejor cumplimiento de la muestra sino a evitar el error no muestral. Ahora bien, todo esto implica invertir mucho dinero, de modo que debemos preguntarnos cuál es el futuro de la encuesta cara a cara. En el Perú se sigue trabajando con este tipo de encuestas porque no se quiere correr el riesgo de 
sesgo que podrian tener las muestras telefónicas o las en línea. Sin embargo, esto implica elevar los costos.

Finalmente, quisiera mencionar una insatisfacción que tengo como investigador y que seguramente ustedes comparten: tenemos muchas encuestas y poco análisis. Hemos generado mucha información sobre comportamiento electoral, sobre valores, creencias, etc. pero todavía no logramos identificar cuáles son los mejores predictores del voto, los predictores del comportamiento político en general. Este no es solo un trabajo de matemáticos, sino también un trabajo de sociólogos y politólogos que tienen que tratar de definir cuáles son las variables independientes que van a ayudarnos a entender el comportamiento político. Comportamiento, por supuesto, que nunca vamos a llegar a predecir en el $100 \%$.

\section{Fabián Echegaray ${ }^{6}$}

Yo creo que, a pesar de que el título del panel es "Fortalezas y debilidades de las encuestas", siempre tenemos un sesgo a concentrarnos básicamente en las debilidades y buena parte de las exposiciones hasta ahora han enfatizado ese punto. Trabajando en Brasil, no tanto con encuestas electorales sino con encuestas de opinión pública pero acompañando las encuestas políticas, y más allá del natural optimismo brasileño que me pueda haber contagiado luego de vivir tantos años allí, parece difícil apenas focalizarse solo en el tema de las debilidades. Basta pensar en el número de encuestas que se hicieron desde la elección de 2002 hasta la última de 2014: se pasó de unas 380 en la elección de 2002 a unas 400 y poco en 2006, a unas 580 en 2010 y en esta última elección se produjeron 2.400 (encuestas electorales, no necesariamente todas nacionales).

Es verdad que en el año 2014 hubo varias equivocaciones. Pero estos números que estamos mencionando no nos hablan de una industria decadente o en crisis o, digamos, con problemas de personalidad; todo lo contrario. Es ver-

\footnotetext{
${ }^{6}$ Director de la consultora Market Analysis (Brasil).
} 
dad que también esto trae aparejado algunos problemas, como algunos free riders, algunos competidores que se suben a la ola y terminan, muchas veces, utilizando métodos no ortodoxos y bastardizando la práctica y, por extensión, la reputación de las encuestas como instrumento, como propuesta de autoconocimiento de la sociedad y con capacidad para establecer algún tipo de diagnóstico.

Las debilidades se reconocen, obviamente, y hubo ciertos desajustes en algunas elecciones a gobernador, básicamente en 5 estados (Brasil tiene 26 estados además del Distrito Federal). Entonces, otra vez estamos hablando de una minoría de casos en los que hubo desajustes que fueron más allá del margen de error. Pero también es importante tener en cuenta los contextos de estas elecciones. Brasil es un sistema multipartidario, en el Congreso están representados 28 diferentes partidos. Cuando yo me fui de la Argentina, en los ochenta, el modelo de funcionamiento era el bipartidismo, y esa idea me acompaño a lo largo del tiempo. Se crearon nuevas formaciones, nuevos partidos y nuevas alianzas, pero todavía creo que todos seguimos pensando en términos de polaridades, de 3 o 4 partidos como mucho. Hoy en Argentina hay 62 partidos actuantes a diferentes niveles, incluyendo subnacionales. Trabajar en contextos de tal fragmentación partidaria es una de las recetas mágicas para cometer errores. De hecho, en Brasil, donde hay un sistema de balotaje en el que terminan compitiendo dos opciones, no fue en las elecciones presidenciales que se cometieron los errores, que de hecho quedaron dentro de los márgenes de error. (En Brasil los grandes players de las encuestas electorales: Ibope, que realiza una encuesta probabilística a la cual termina haciendo unos ajustes por cuota al final, y Folha de São Paulo, que hace encuestas en puntos de concentración, interceptando a las personas en la calle y usando tamaños de muestra 4 o 5 veces más grandes que los de Ibope. Y los resultados de ambas encuestadoras fueron muy parejos).

Ahora bien, donde sí hubo errores fue en los contextos de excesiva fragmentación, en los que había 6 o 7 candidaturas 
con altas chances de competir. Esto sucedió en el estado de Rio Grande do Sul, por ejemplo, donde quien aparecía tercero en las encuestas terminó ganando la gobernación; también en el estado de Bahia. Pero, otra vez, fueron 5 de los 27 estados los que de hecho experimentaron este tipo de desvío más allá del margen de error.

Repasando ahora un poco las intervenciones, uno tiende naturalmente a caer en dos tipos de tentaciones: una es culpabilizar a nuestra materia prima, a nuestros encuestados, pensando que por volatilidad, por individualización, porque ha habido una pérdida de las formas tradicionales de crear identidad, han dejado de ser confiables. Y muchas veces atribuyéndoles segundas intenciones a la hora de manifestarse. Es un problema que encontramos en encuestas de opinión pública y en estudios de mercado, no solo en las encuestas electorales. Y que tiene que ver con nuestra propensión a descansar en las mismas variables de referencia, variables que son vinculadas a cualquier modelo tradicional de anclaje social y de los comportamientos: el individuo responde a una clase social o a una identidad partidaria o a algunas manifestaciones institucionalizadas del proceso de socialización que atravesó durante su vida. Estas son interpretaciones que en la propia academia ya fueron superadas, y no ahora, sino hacia fines de los años setenta u ochenta, por ejemplo, con la perspectiva del voto económico. La idea de que el elector vota a alguien de su propia clase o vota por el partido con el que se identifica ya no funciona. Y esto, como decía antes, no es nuevo. Ya hacia fines de los ochenta surgieron otras formas de interpretación vinculadas a una racionalización subyacente: sea la de premiar una gestión económica exitosa, sea porque le trajo al votante éxito personal o porque fue una palanca para el crecimiento del país $\mathrm{y}$ ahí entonces funciona algún tipo de patriotismo económico vinculado a la idea de plebiscitar favorablemente al gobierno de turno en función de los resultados económicos.

Junto con la idea del voto económico aparecieron otras alternativas para poder dar cuenta de esa variación en la 
forma de elección de los individuos, alternativas que pasaron a tener un grado de éxito mucho mayor que la identidad partidaria o la clase social. Estas alternativas tienen que ver con la identificación, con la simpatía, con la reacción emocional que se genera con los candidatos y, de hecho, hay ríos de literatura y de ejercicios experimentales en los que justamente lo que se hace es ver las reacciones de empatía, las emociones que despiertan las imágenes o los discursos según el tipo de acentuación de la voz, según las formas de modular que tiene cada uno de los candidatos, etc. Porque ahí se supone, en función de ese proceso de individualización y de destradicionalización que ya ha sido estudiado principalmente por la sociología, que el tipo de lazo que se construye con aquel que se va a elegir para ocupar el gobierno es de naturaleza emotiva o vinculado al tipo de estilo de vida que uno tiene, y no vinculado a la ideología. A veces pecamos de querer hacer funcionar nuestra materia prima bajo premisas que, de hecho, hace rato que no responden a aquellos criterios.

Como forma de cerrar el tema quisiera volver sobre nuestro sesgo para enfatizar debilidades. Claro, aprendemos cómo son las debilidades e intentamos superarlas, pero no quisiera dejar de destacar el lado de las fortalezas. Las debilidades son vinculadas a los errores, al hermetismo con que muchas veces comunicamos los resultados o a la opacidad con que los medios de comunicación muchas veces divulgan esos resultados. Hay también un abuso de los resultados de los estudios de opinión pública por parte de los políticos o de los medios o de nosotros mismos como consultores. Está muy fresco el caso del proceso de destitución a Dilma Rousseff, en el que opositores, columnistas, ONG vinculadas con redes sociales a favor o en contra de dicho proceso de destitución cristalizaron de forma muy clara la idea de que Dilma fue juzgada por el conjunto de la obra, por su impericia, cuyo indicador más claro era lo mal que era juzgada en las encuestas de opinión, en las encuestas de evaluación de desempeño. Así, la causa legal de 
su enjuiciamiento, que fue la contabilidad creativa que Dilma estuvo desarrollando durante los dos mandatos, quedó realmente diluida. Fue ese tipo de uso incorrecto o de abuso de los datos de opinión pública lo que permitió que un sistema presidencialista funcionara de forma parlamentaria y se resolviera de esa forma casuística y ad hoc una gran crisis política. No hubo ningún tipo de manifestación institucional ni ninguna consultora que intentara diferenciar las aguas. De hecho, una interpretación de un proceso político exclusivamente a caballo de datos de opinión pública terminó siendo, en parte, el discurso no formal sobre por qué Dilma debía irse en lugar de ser sustituida.

Las fortalezas remiten a las fuentes. Manuel Mora y Araujo comenzó recordándonos a algunos precursores, como Gallup. Gallup pensaba que las encuestas y los estudios de opinión pública en general eran una forma de hacer hablar a la mayoría silenciosa más allá de las elecciones, pudiendo extender de alguna forma la presencia y la representatividad de las preferencias que los electores, los ciudadanos en general, tienen, más allá de la ocasión específica de votar en una urna cada cuatro o cada dos años, y también destacando su papel como mecanismo de fiscalización, de accountability, de poder transparentar hasta qué punto determinadas decisiones de los gobernantes reflejan lo que los representados, de hecho, votaron. Por otro lado, es verdad que, frente a la idea de que las encuestas permiten generar ese canal de expresión o ser esa oportunidad de voz de las mayorias, se antepuso la duda de varios intelectuales influyentes que cuestionaban hasta qué punto lo público, la propia idea de opinión pública, existe en realidad. Para Lippman, por ejemplo, las encuestas reflejan un temario de elites que, en formato de paquete, se presentan como opciones de respuestas ya predefinidas a los electores y no son, por lo tanto, oportunidades de generación razonada o reflexiva de opiniones por parte de quien responde. Pero, en fin, más allá de estas polémicas, de estas críticas a las forta- 
lezas que Gallup enunciara, me parece que es importante aprovechar una reunión como esta para enfatizarlas y no dejarlas latentes.

\section{Ignacio Zuasnabar7}

Las encuestas electorales parecen estar atravesando ciertos problemas a nivel global. Esto no es una novedad y en mi opinión, por más que haya ciertas fortalezas, tiene más sentido trabajar sobre las debilidades.

Una primera tiene que ver con cambios en el objeto de estudio. Los votantes se mueven más rápido, se mueven más rápido para todo. Cambian más rápido de pareja, cambian más rápido de marca de champú, cambian más rápido de todo. Quizás no de equipo de fútbol, que es lo único que permanece más estable, pero obviamente cambian más rápido de preferencias electorales. Esto no debería sorprendernos, pero nos sorprende. Y resulta que cuando una encuesta de una semana no se confirma a la semana siguiente es una verdadera complicación, cuando en realidad ya sabemos que esto es así. Esto tiene que ver con los cambios en nuestra sociedad, con la perdida de las identidades partidarias, etc. y, efectivamente, es una fuente de problemas para las encuestas preelectorales.

Tenemos una segunda fuente de problemas que tiene que ver con cambios en los métodos. Nosotros veníamos de una etapa de hacer encuestas con blancos fijos, con electores fijos, con métodos calibrados. Entonces, la verdad es que era bastante fácil. Si uno tiene un blanco fijo y un arma que esta calibrada... la verdad que acertarle no resulta muy complicado. Pero ahora parece que el blanco se mueve, que el arma empieza a tener problemas, y el margen de precisión, efectivamente, disminuye.

Esto tiene que ver con varias cosas. Una es el aumento significativo de la tasa de rechazo. En efecto, los ciudada-

${ }^{7}$ Director del Área de Opinión Pública de Equipos Consultores (Uruguay); Vicepresidente de Wapor Latinoamérica. 
nos en el mundo entero, para nuestro pesar, contestan cada vez menos encuestas. El Pew Research Center de Estados Unidos, que estudia mucho estos temas, publicó hace poco un reporte en el cual estima que la tasa promedio de respuesta a las encuestas norteamericanas es del 9\%. Esto significa que de 100 integrantes de una muestra original pura se llega solamente a 9, los 91 restantes no responden. El reporte también dice que, por razones que escapan al conocimiento de los matemáticos -probablemente para poder explicarlo deberíamos recurrir a lo divino, a lo celestial-, ese $9 \%$ se parece bastante al $100 \%$. Hay un error derivado de esto pero no es mayor. Pero, bien, efectivamente la gente nos contesta menos.

Un segundo tema de cambio de los métodos tiene que ver con cuestiones ligadas a los costos. Por lo general, las empresas que trabajamos en este campo estamos en entornos competitivos. Dependemos de clientes que pagan y la variable costo es relevante. Hay un conjunto de procedimientos que afectan a los métodos, que han perdido calidad respecto de hace 20 años y que, obviamente, también tienen un impacto en los resultados.

Una tercera cuestión tiene que ver con el cambio en los hábitos de comunicación de las personas. Hace 20 años uno llegaba a una casa, tocaba el timbre, decía que quería hacer una encuesta y ese hecho le cambiaba la tarde al entrevistado. Hoy la gente ya no atiende los timbres de las casas, ya no atiende los teléfonos fijos, que son casi un objeto de museo. En mi casa pasa siempre que, si suena el teléfono fijo, son mi madre o mi suegra; no hay ninguna otra chance de que suene el teléfono fijo en mi casa. Sin embargo, muchas encuestas en el mundo todavía se hacen a teléfono fijo por razones que tienen que ver con los costos o con carencias de otras técnicas. La gente hoy en día se comunica básicamente a través del teléfono celular y este cambio de tecnología ha sido mucho más rápido que nuestra capacidad para implementar nuevas técnicas. Yo fantaseé hace tres años con la idea de hacer encuestas 
por Whatsapp. Pero no es tan sencillo; nos enfrentamos a enormes desafíos de costos y de riesgo. Y lo peor de todo es que quizá dentro de tres años Whatsapp ya habrá quedado superado y habremos terminado desarrollando un método que en poco tiempo quedó obsoleto.

Y, finalmente, hay cambios en los medios. Esto no se ha tratado mucho, lo mencionó al pasar Eduardo. Los medios han cambiado mucho en estos 20 años, lo que afecta nuestra actividad. Porque la capacidad que tenemos nosotros de hacer un pronóstico con un cliente privado lo manejamos de manera diferente que con el conjunto de la población, donde los medios son los canales a través de los cuales nos comunicamos. Aquí hay una cuestión de inmediatez de la información, de la información de 140 caracteres, de búsqueda del titular original que, obviamente, limita mucho lo que la encuesta pueda decir. Los medios ofrecen pocas posibilidades de dar un contexto razonable en el que uno pueda explicar los límites de la técnica. Y eso es un problema.

Hay un segundo elemento que tiene que ver con que los medios ponen más énfasis en los errores de las encuestas que en los aciertos. Si uno mira el registro de las encuestas electorales en el mundo, si bien está claro que tenemos más problemas que antes, también está claro que las encuestas aciertan mucho más de lo que se equivocan. Un gravísimo error de las encuestas en Brasil probablemente se publica en varios medios del continente, en tanto en caso de un acierto espectacular en Perú (no tanto por el conteo rápido del escrutinio, que trabaja con volúmenes de datos importantes, o el boca de urna, que mide el comportamiento pasado, sino porque acertaron con las encuestas preelectorales), casi nadie se entera. El nivel de precisión que tuvieron los encuestadores en Perú no es noticia, ningún medio lo va a publicar razonablemente. Si yo fuera editor quizás tampoco lo publicaría. Pero las cosas son como son: se difunden más los errores de las encuestas que los aciertos y esto nos afecta.

Un tercer elemento que hace a la construcción de las imágenes sobre las encuestas se muestra en un trabajo re- 
ciente en los Estados Unidos, que demuestra que sistemáticamente los medios les dan más espacio a las encuestas desviadas, a las encuestas con escenarios más originales, que a las que están dentro del parámetro. En países donde hay muchísimas encuestas, una que dice lo mismo que dijo la semana anterior o lo mismo que están diciendo todas no se publica; qué sentido tendría hacerlo. Ahora bien, una encuesta que muestra un resultado distinto, probablemente de forma acrítica, sin especificar cuáles fueron los métodos utilizados o quién es el encuestador, esa sí tiene espacio porque está mostrando un escenario distinto. Y eso ayuda a construir en la gente la sensación de que hay más variabilidad entre las encuestadoras de lo que efectivamente hay.

El diagnóstico, entonces, si tenemos en cuenta todos estos problemas. Yo diría que estamos complicados. La verdad, lo que sentimos los encuestadores es que, más allá de las fortalezas, estamos complicados.

¿Qué hacer? Lo único que no podemos hacer es quedarnos de brazos cruzados. Entonces voy a intentar ahora, con un poquito de atrevimiento, sugerir algunas cosas en estos tres planos.

En el plano de los electores, lamentablemente no podemos modificar nada: los electores van a seguir siendo volátiles, van a seguir definiendo su voto a último momento y, a decir verdad, en ese sentido no hay mucho para hacer. Nos gustaria, pero simplemente hay que asumirlo. Los electores son como son.

En relación a los métodos, y con la ruptura o el resquebrajamiento del paradigma que nos decía cómo hacer las cosas, creo que esto es una amenaza pero también podemos verlo como una oportunidad. Así como la irrupción de la tecnología es una amenaza a cómo venimos haciendo las cosas, es también una tremenda oportunidad para acercarnos al público, de eso no hay duda. Y aquí voy a decir dos cosas en sentido contrario, voy a hacer como el expresidente uruguayo Pepe Mujica, que tenía una frase: "Como te di- 
go una cosa, te digo la otra". Así, sin ningún problema. Acá no voy a llegar al nivel del Pepe Mujica, pero creo que: por un lado tenemos que ser más ortodoxos que nunca, respetar la ortodoxia más pura (de hecho, el caso peruano, que es un caso exitoso de extrema precisión de las encuestas electorales, las encuestas fueron cara a cara y con rigor probabilístico importante). Por ejemplo, las revisitas. ¿Cuántas veces tenemos que revisitar un hogar cuando no encontramos al titular o volver a llamar si se trata de una encuesta telefónica? Quizás muchos problemas de las encuestas telefónicas tienen que ver con que no rellamamos. Claro, es más caro, lleva más tiempo. Pero hay que intentar volver las muestras más puras desde el punto de vista probabilístico. Y esto lo digo a pesar de que soy un defensor de las cuotas, como Marta sabe. Defender las cuotas no quiere decir claudicar, hay que ser lo más probabilístico posible en todo el proceso. Y creo que ese es un buen camino. En Uruguay estamos ensayando ya desde hace un tiempo con encuestas a teléfonos celulares con discado digital aleatorio. Y la verdad es que la probabilidad funciona. Las encuestas a celulares, por más que la gente tenga más de un celular, tienen un nivel de precisión muy grande. En las últimas elecciones departamentales de Montevideo hice tres encuestas en simultáneo y con las mismas preguntas. Fue un experimento autofinanciado: hicimos una encuesta cara a cara, una a celulares y una en línea y las tres anduvieron bastante bien, las tres predijeron al ganador, las tres dieron dentro de los parámetros razonables. La encuesta en línea se desvió entre dos candidatos del mismo partido (predijo bien el partido y el orden, pero no estimó del todo correctamente la diferencia entre los dos candidatos del partido principal, el Frente Amplio). Pero la encuesta que mejor anduvo fue la de la telefonía celular y, en segundo lugar, la cara a cara. Y la encuesta a celulares fue sin rellamados. Todavía las tasas de respuestas de la gente en Uruguay a encuestas a celulares -supongo que acá ocurre lo mismo- son altas. El llamado a celulares todavía tiene en la gente ese efecto del timbre 
hace 30 años. Hay que llamar al celular, no al teléfono fijo. No sé cuánto va a durar esto, pero tenemos aquí una ventana de dos o tres años para trabajar, aunque posiblemente esto va a migrar rápidamente hacia las encuestas en línea.

Lo primero, entonces, que quería decir es que hay que ser más ortodoxo que nunca en términos de volver a hacer nuestras muestras lo más probabilísticas posible. Otras de las ideas que probablemente haya que explorar es el tema de los incentivos. ¿Qué pasa con los incentivos? Si el problema es la tasa de respuesta, ino podemos mejorarla con algún incentivo, que no signifique pagarle 20 dólares a cada individuo, sino tener un incentivo más original? No sé, tener el sorteo de un Iphone. Algo que pueda ser más atractivo, esas cosas creo que las hemos probado menos de lo que deberíamos.

Lo segundo que voy a decir es, en algún sentido, lo contrario de lo que acabo de decir: debemos animarnos a salir de la zona de confort, debemos animarnos a salir de lo que sabemos. Y creo que tenemos que hacer ambas cosas al mismo tiempo: combinar métodos, animarnos al multimodo, animarnos a hacer encuestas por Whatsapp, animarnos a hacer encuestas en línea, otras por teléfono fijo, otras por celular y otras cara a cara. Esto tiene millones de problemas, los matemáticos o estadísticos a los que hacía mención Marta nos matarían, pero igual ya nos matan. Así que, en definitiva, perdido por perdido, creo que tenemos que ensayar con el multimodo. Vamos cada vez más hacia lo no probabilístico, sobre todo en la encuesta en línea, en la que ni siquiera es posible estimar la tasa de no respuesta. Me acuerdo, hace como 10 años, un profesor de la Maestría en Comunicación Política que coordino en la Universidad Católica del Uruguay dijo en su curso algo así como: "Yo creo que en esto vamos a muestras coincidentales, ajustadas salvajemente por cuotas y no deberían funcionar mucho peor". Me pareció superprovocativo, me dejó pensando. Yo creo que ahora lo en línea podría sonar parecido. Hoy por hoy, tenemos una ventaja en esta línea, y es que los 
sistemas de procesamiento permiten hacer ponderaciones mucho más complejas, mucho más que la matriz doble que hacíamos ponderando por una o dos variables. Hoy, para corregir muestras no probabilísticas, se hacen ponderaciones por $n$ cantidad de variables; esta es una de las cosas que podemos mejorar. En algunos estados de Estados Unidos algunas encuestadoras están ponderando por variables actitudinales. Yo en Uruguay pondero por voto anterior, que no es una variable actitudinal pero es, en última instancia, el recuerdo del voto. Esto es posible en un país como Uruguay, con partidos sólidos, pero en otros contextos es más difícil. Ponderar las muestras por variables actitudinales además de por variables duras es todo un campo nuevo para calibrar las muestras. En fin, yo creo que hay que volver a hacer todo esto para volver a recuperar calibre en todos nuestros métodos. No creo que vaya a ser un proceso rápido, pero me parece que no tenemos muchas otras alternativas que empezar a ensayar, como siempre fue.

Tenemos también la cuestión de los medios, en realidad, más que de los medios, de nuestro posicionamiento público. Acá voy a ser un poco provocativo, pero si efectivamente nuestro prestigio, nuestra legitimidad, nuestra credibilidad está dada por nuestra capacidad para pronosticar un resultado con precisión, y si esa capacidad está amenazada por esa serie de factores que estamos analizando, ¿no tendrá sentido claudicar de esa función? ¿Ser más explícito en esto? De hecho, Gallup en Estados Unidos acaba de anunciar que no va a hacer más pronósticos electorales, que se retira de esta función. Va a hacer encuestas, va a medir actitudes, va a dar insumos para el seguimiento de la campaña, pero no hace más pronósticos electorales. Para mí eso es como una puñalada en el corazón, pero, sin tener que llegar a eso, tal vez tengamos que "matar al gurú". Durante muchos años hemos ganado credibilidad por la idea de que somos una especie de gurú, que tenemos una especie de bola mágica, pero, bueno, si seguir diciendo eso nos juega en contra, no por razones interesadas sino 
porque las condiciones realmente han cambiado y quizás la bola de cristal ya no funciona tan bien como antes, quizás lo más sano es decirlo. ¿Qué pasa si lo decimos? ¿Será muy grave el asunto? Creo que no. Creo que, en última instancia, tenemos que construir un nuevo relato, una nueva especie de pacto social sobre lo que las encuestas pueden dar. Esto implica explicar el rol fundamental de las encuestas, que es entender el mundo y ayudar a tomar mejores decisiones desde muchos ámbitos. Si estamos convencidos de eso, de que eso es lo más valioso de las encuestas y que es lo que las encuestas hacen muy bien, bueno, digámoslo. Y digamos también que tenemos más problemas para pronosticar con precisión el resultado de una elección. Asumir los límites de la técnica como herramienta de pronóstico, señalar claramente la existencia del late swing, el cambio de voto a último momento como un problema. La encuesta no es una herramienta de pronóstico -como dijo Marta-, es una herramienta de medición en un momento dado, que hace referencia a un futuro posterior. También Manuel lo dijo al principio. Deberíamos decir más estas cosas. Señalar claramente los límites de llegada a ciertos públicos, no es ningún pecado, es explicitar algo que no siempre decimos. Yo creo incluso que a veces ocultamos qué es el error muestral, los intervalos de la confianza. Ustedes me dirán: "No, no lo ocultamos, está en la ficha técnica" Sí, pero es una forma elegante de ocultarlo. ¿Cuántos de nosotros presentamos resultados con intervalos de confianza? ¿Cuántos de nosotros al presentar datos decimos: "Bueno, la intención del voto hacia el partido A va a estar entre el $51 \mathrm{y}$ el 45? Ustedes me dirán que entonces nadie nos va a contratar... y puede ser. Pero los medios igual cada vez pagan menos por encuestas, por lo menos protejamos un poquito nuestro prestigio.

Para terminar, algunas cuestiones tipo autocrítica, como, por ejemplo, evitar lecturas polarizadas. El otro día, mirando unas encuestas en México sobre actitudes de los mexicanos hacia los candidatos presidenciales en Esta- 
dos Unidos, la pregunta que se les aplicaba a los encuestados era: "Pensando en Hilary Clinton, iusted tiene hacia ella simpatía u odio?"; "y con Donald Trump, iusted tiene simpatía u odio?" Eso fue publicado y mostraba que el $80 \%$ de los mexicanos sienten odio por Donald Trump y simpatía por Hilary Clinton. ¿No estará un poco simplificada la escala? Es decir ¿no habrá matices en la opinión pública? Ese es un error totalmente nuestro, no es atribuible a los medios, estamos haciendo un disparate. Ya lo de preguntar evaluación de gestión presidencial con punto medio o sin punto medio es toda una discusión, pero esto es un ejemplo muy evidente de lo que no se debería hacer. Lo mismo con la intención de voto. Si todos sabemos que el voto es menos firme, que la intención es más volátil, ¿por qué preguntamos tanto? ¿Por qué forzamos una, dos, tres, cuatro veces una respuesta, casi que lo agarramos al entrevistado del cuello, para reportar el menor porcentaje de indecisos? ¿No será mejor reportar lo más cercano a la verdad: que hay más indecisos que antes, que nuestras preguntas de hace 30 o 40 años interpelaban a otro tipo de ciudadano? ¿No tendremos que reportar eso de manera más abierta? Seguramente sí, y eso está en nuestra responsabilidad. Yo creo que en el fondo nos gusta jugar a esto del gurú, pero, dado que ya no rinde, es posible que tengamos que pensar en otra estrategia.

Más allá de que esto pueda sonar algo apocalíptico, también es cierto -y creo que es parte de lo que todos queremos decir- que, a pesar de todos estos problemas que tenemos y vamos a seguir teniendo, las encuestas siguen siendo el mejor método para estimar lo que puede ocurrir en una elección. Yo no viví un mundo sin encuestas, no lo recuerdo, pero a veces trato de hacer el esfuerzo de imaginarme lo que sería una elección sin encuestas y realmente me parece horrible. Las encuestas se equivocan, pero, incluso con todos sus problemas, todavía siguen siendo la mejor herramienta no solo para entender la realidad sino para anticipar lo que puede llegar a ocurrir. 